\title{
Growth and Instability in Cotton Cultivation in Northern India
}

\author{
Sanjay*, M. Seidu and K.K. Kundu \\ Department of Agricultural Economics, CCS Haryana Agricultural University, Hisar, Haryana, India \\ *Corresponding author: sanjaybhyan@gmail.com
}

\begin{abstract}
The cotton industry has witnessed many technological breakthroughs as well as policy changes. Setbacks such as disease and pest infestation and erratic rainfall patterns continuously confront cotton cultivation. These continuous changes and confrontations invariably affect the trend, growth and stability of the economic performances of cotton. Hence, based on secondary data from 1966-67 to 2013-14, the study assessed the trends, growth and instability in area, production and yield of cotton in Haryana using semilog linear function, compounded annual growth rate and Cuddy Della Valle Index. The study revealed a positive significant $(\mathrm{P}<0.01)$ trends with low annual growth rates of area of harvest $(2.00 \%)$, production $(3.99 \%)$ and yield (1.66\%). Instability was high and also inclined at an annual rate of 30.96\% in area, $25.76 \%$ in production and $28.04 \%$ productivity in the same order. The study, therefore, recommended the development and spread of innovations at an affordable price to farmers. Effective disease and pest control measures should be developed to check the perennial pest infestation of cotton in the state.
\end{abstract}

Keywords: Cotton, Instability, Cuddy Della Valle Index, Cochrane-Orcutt

Cotton occupies about 5 percentage of the total cropped area in India and it is grown in more than $11 \mathrm{M}$ ha. Covering different agroclimatic zones of the country. About 74 percentage of the total area and production of cotton in the country are contributed by four states of Gujarat, Andhra Pradesh, Maharashtra, and Telangana. The other states like Madhya Pradesh, Rajasthan, Haryana, Karnataka, Tamil Nadu and Rajasthan supply rest of the output of the crop. However, in the northern part of India Haryana is the main producer of cotton followed by Punjab and Rajasthan. The share of Haryana in total area and production of cotton in the country is about 6.77 percentage and 11.91 percentage respectively. Cotton in the state is cultivated mainly grown in irrigated areas of districts like Fatehabad, Bhiwani, Jind and Sirsa districts which together account for 94 percentage of the state's output of cotton.

Haryana state's economy is consistently influenced by cotton through its production and processing sectors, and by generating direct and indirect employment to more than 50 million people. The rippling benefits of cotton cultivation do not only influence state's economy but the whole of Indian's economy also. The continuous reliance of the cotton industry in Haryana will imply that, increase in the production and productivity levels of the crop is assured. Likewise, it also implies maintaining stability in the economic performance (i.e. area, production and productivity) while prioritising sustainability to feed the growing markets of the local and national economy.

Increased instability in agriculture augments the risks involved in farm production and adversely affects farmers' income and decisions to adopt modern technologies and make investments in farming.

In order to make proper decision or policy to improve on production, productivity and ensuring stability, the decision has to be guided by certain decision elements (such as the pattern, trend, growth rate, instability, and relationships that exist among the economic performance of the crop). The cotton industry has experienced series of policy interventions, technological progress, pests and 
disease infestation and climate variations over the years (Agarwal et al. 2007; Tripathi and Prasad 2009; Choudhary and Gaur 2010; Khadi 2012; Suresh et al. 2013). Hence, it becomes more relevant if careful emphasis is levelled on the above mentioned decision elements. These decision elements though constantly varying but have greater effects on the crop improvement as well the livelihoods of the millions of farmers.

In a nutshell, policy directions to strategically improve the economic performance of cotton in Haryana without considering the decision variables that affects its performance would not make much relevant impact and would be characterized by doubt. Hence, the paper focused to estimate the trends, compound growth rate and instability in area, production and productivity of cotton in Haryanaby utilizing time series data for the period from 1967-2014. Further, the paper also estimated the relationship between the effects of area on production.

\section{Database and Methodology}

Time-series data from secondary sources for 48 years (1966-67 to 2013-14) pertaining to area of harvest, production and productivity of cotton on Haryana were sourced for the study. The data were sourced from various issues of published sources such as Indiastat; Agricultural Statistics at a Glance and other published sources.

The study determined the trend, growth rate, instability, and the effect of change in area on production and productivity of crop for the period 1966-67 to 2013-14 by employing analytical techniques such as arithmetic mean, standard deviation and coefficient of variation.

A parametric model such as semi logarithmic function was fitted to estimate compound growth rate while the Cuddy-Della Valle index was specified to estimate instability in area, production and productivity. Cochrane-Orcutt (CORC) iterative procedure was adopted in instances to correct the estimate where autocorrelation was prevalent.

The t-test statistic was also employed to test the significance of the compound growth rate and the coefficients that were estimated. Similarly, the F-test statistic was used to test the significance of the specified parametric models.

\section{Model specification of trend and compound growth rate}

Similar to the studies of Wassim (2001) and Laxmanan et al. (2005), the study specified growth rates of area; production and productivity using semi-log linear function. Since the dependent variable(s), area/production/productivity (Y) grows exponentially at an unknown rate $(r)$. Therefore, the study specified the models below to estimate trend (equation 1), growth rates (equation 1 and 1.1) of area; production and productivity of the selected crops.

$$
\begin{aligned}
& \log Y_{i}=\beta_{0}+\beta_{1} t_{i}+\varepsilon_{i} \\
& \therefore r=\left(\text { Anti } \log \beta_{1}-1\right) \times 100
\end{aligned}
$$

\section{Model specification of instability}

The study also measured the index of instability of area, production and productivity of the selected major field crops (wheat, paddy, cotton, rapeseed and mustard, sugarcane and pearl millet) by using Cuddy-Della Valle index. The coefficient of variation around the trend $\left(\mathrm{CV}_{\mathrm{t}}\right)$ rather than co-efficient of variation around the mean $(\mathrm{CV})$ was used. Thus, a log linear trend model and CV were fitted to estimate instability. Cuddy Della Valle Instability index (Cuddy \& Della, 1978 and Della, 1979) is a modification of $\mathrm{CV}$ to accommodate for trend, which is commonly present in time series economic data. This method is superior over other scale dependent measures such as standard deviation or Root Mean Square of the errors (RMSE) obtained from the fitted trend lines of the raw data, and hence suitable for cross comparisons

The same semi log linear trend model that was specified for the indices of area, production and productivity in equation (1) was again used in the estimation process of instability thus,

$$
\log Y_{i}=\beta_{0}+\beta_{1} t_{i}+\varepsilon_{i}
$$

Where:

$Y_{i}=$ dependent variable specifying Area (000 ha) or production (000 bales) or productivity ( $\mathrm{kg} / \mathrm{ha}$ )

$\beta_{0}=$ the intercept, $\beta_{1}=$ the parameter to be estimated, $t_{i}=$ time in years and $\varepsilon_{i}=$ the error term. 
The index of instability (i.e. the Cuddy-Della Valle index which corrects the coefficient of variation) was constructed by considering the $R^{2}$ obtained in the log linear trend model and the coefficient of variation around the trend. The Cuddy-Della Valle index was constructed as follows:

$$
C V_{t}=C V \times \sqrt{1-R^{2}}
$$

Where:

$C V_{t}=$ Coefficient of variation around the trend $C V=$ Coefficient of variation around the mean $R^{2}=$ coefficient of determination from a time-trend regression.

From equation (2), the co-efficient of variation (CV) around the mean was multiplied by the square root of the proportion of the variation, which was unexplained by the trend equation;

$$
\begin{aligned}
& Y_{i}=\beta_{0}+\beta_{1} t_{i}+\varepsilon_{i} . \\
& C V=\frac{S D}{A M} \times 100
\end{aligned}
$$

Where:

$S D=$ Standard deviation of area (000 ha) or production (000 bales) or productivity ( $\mathrm{kg} / \mathrm{ha}$ )

$A M=$ Arithmetic Mean of area (000 ha) or production (000 bales) or productivity (kg/ha).

Prior to running the empirical specified models, autocorrelation was taking into account. CochraneOrcutt (CORC) iterative procedure was adopted in instances where autocorrelation existed to correct the estimate. This procedure uses a twostep procedure that tries to estimate the amount of correlation $(\rho)$ between pairs of residuals and also uses the generalized differencing to make use of this estimated correlation. Generalized differencing tends to remove the serial correlation.

$$
Y_{t}=\beta_{0}+\beta_{1} X_{t}+\varepsilon_{t}
$$

Problem of autocorrelation in equation (3) was corrected by adopting CORC transformation; the transformation is simplified below: as,

$Y_{t}-\rho Y_{t-1}=\beta_{0}(1-\rho)+\beta_{1}\left(X_{t}-\rho X_{t-1}\right)+\mu_{t}$
Equation 3.1 can be rewritten as follows:

$$
Y_{t}^{*}=\beta_{t}^{*}+\beta_{1} X_{t}^{*}+\varepsilon_{t}
$$

Where:

$$
\begin{aligned}
& Y_{t}^{*}=Y_{t}-\rho Y_{t-1}, \beta_{0}^{*}=\beta_{0}(1-\rho) \text { and } X_{t}^{*}=\left(X_{t}-\rho X_{t-1}\right) \\
& \text { for } t=2,3, \ldots n
\end{aligned}
$$

The transformation that generates the variables $Y_{t}^{*}$ and $X_{t}^{*}$ is referred to as quasi-differencing or generalized differencing. $\beta_{t}^{*}$ is the new intercept. It must be emphasized that the stochastic term in (3.3) satisfies all the assumptions of OLS and estimates that are BLUE.

\section{RESULTS AND DISCUSSION}

\section{Area of harvest, production and productivity of cotton (1967-2014)}

From Table 1 it was observed that, the total area of cotton harvested from the period 1966-67 to 2013-14 vary between 183 ha to 653 thousand ha. Similarly, the production level ranges from 305 to 2,616 thousand bales. Furthermore, the productivity level of cotton also varies from 195 to $739 \mathrm{~kg} /$ ha. The average area of harvest, production and productivity levels of cotton were 429 thousand ha; 1,058 thousand bales and $400 \mathrm{~kg} / \mathrm{ha}$ respectively with their respective standard deviations as 150 thousand ha, 600 thousand bales and $132 \mathrm{~kg} / \mathrm{ha}$.

Table 1: Characteristics of cotton in terms of its economic outputs in Haryana

\begin{tabular}{cccc}
\hline \multirow{2}{*}{$\begin{array}{c}\text { Descriptive } \\
\text { Features }\end{array}$} & \multicolumn{3}{c}{ Economic Variables of Cotton } \\
\cline { 2 - 4 } & $\begin{array}{c}\text { Area } \\
\text { (000 ha) }\end{array}$ & $\begin{array}{c}\text { Production } \\
\text { (000 bales) }\end{array}$ & $\begin{array}{c}\text { Productivity } \\
\text { ( kg/ha) }\end{array}$ \\
\hline Mini & 183 & 305 & 195 \\
Max. & 653 & 2616 & 739 \\
Mean & 429 & 1058 & 400 \\
SD & 150 & 600 & 132 \\
\hline
\end{tabular}

Source: Author's calculation based on data obtained from published sources

\section{Patterns and Trends in performance of cotton in Haryana (1967-2014)}

Figs. 1 - 4 depicted the trends in area (Fig. 1 and 4), 
production (Fig. 2 and 4) and productivity (Fig. 3 and 4 ) of cotton. The trends of the performances of cotton showed positive irregular growth throughout the entire period based on the log linear graphs in Fig. 1 - 4. However, the portrayed series of the five period moving averages in (Fig. 1 - 4) were used as a buttress to confirm the described earlier trends. From the smoothen series' it was confirmed that, the area, production and productivity of cotton showed irregular increase from one period to the other. However, according to Tripathi and Prasad (2009) the continuous improvement in cotton production from 1966-67 onwards was mainly due to yield (via the introduction of 1 hybrids, increased machine power, chemical fertilizers and pesticides). Critical observation of the series of area of harvest, production and productivity suggested a dwindling performance of cotton from 1997 to 2002 . The decline in the performance of cotton attributed due to many factors but the prominent among was the infestation of cotton plant with mealy bug first reported in 1997 and American bollworm causing serious damage to cotton in Haryana. Khadi (2012) also confirmed similar results. The sharp improvement in production and productivity from 2002 (See Fig. 4) was due to the introduction of BT cotton in India. The initial stagnation of area of harvest (see Fig. 1) after the introduction of Bt cotton was compensated by high production and productivity in Haryana.
During this same period cotton growing areas in the states of Gujarat and Andhra Pradesh, Andhra Pradesh, Punjab, Karnataka, Rajasthan, Madhya Pradesh, Orissa, and Uttar Pradesh observed an increased in cotton area which was contrary to the situation in Haryana and Tamil Nadu (Directorate of Cotton Development, 2009). The good monsoon and high producer's prices were among other factors that increase the acreage of harvest of cotton in the states that recorded increase in cotton area.

Nonetheless after 2010, the area of harvest witnessed expansion which according to Adam and Dhruv (2015) (2015) was due to increased predictability and stability of cotton cultivation.

The test of autocorrelation of the data sets unveiled that; the residuals of the data sets were correlated. Hence, autocorrelation were corrected prior to estimation of the trend of the performances of cotton. From Table 2 the level of correlation ( $\rho$ ) between pairs of error terms of the original models (see Fig. 1 - 3) estimating the trend in area, production and productivity were $0.7929,0.3394$ and 0.4374 respectively. The estimates of $\rho$ unveiled that, the original models estimating the trend for area, production and productivity have a problem of autocorrelation. The CORC transformations of data sets in Fig. 1 - 3 were summarised in Table 2. The DW values of 1.9105 (area), 1.9127 (production)

Fig. 1: Trends in area of cotton in Haryana (1967-2014)

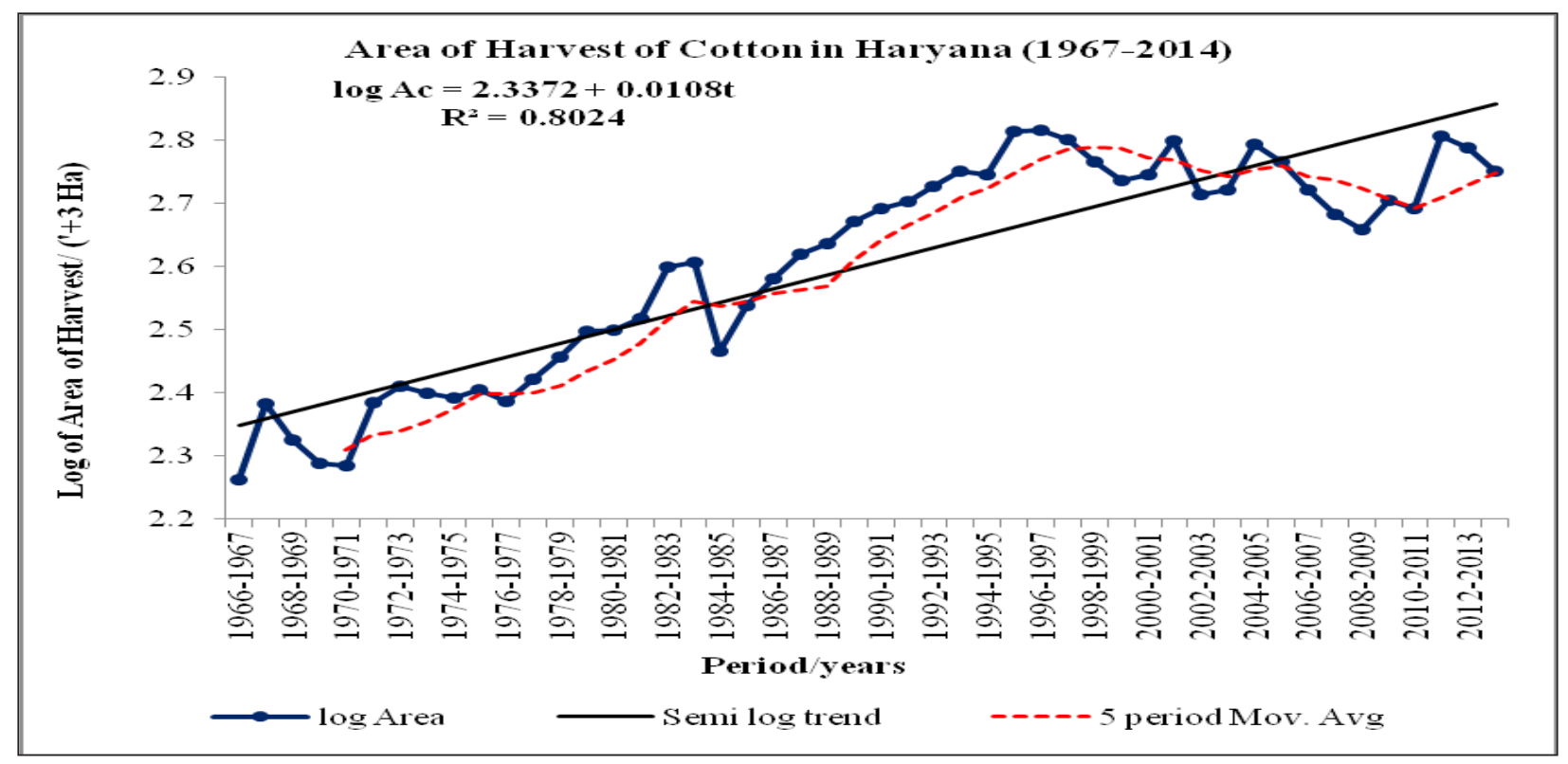

Source: Author's calculation based on data obtained from published sources 
and 2.0702 (productivity) of transformed models proofed that there were no problem of serious autocorrelation.

The estimated semi log trends for area, production and productivity were shown in Table 2 . The test of significance of the models indicated that the null hypotheses that the models contain only constants (intercept) were decisively rejected at $(\mathrm{P}<0.01)$. The measure of the goodness-of-fit shows F statistic of 12.4065 (area), 173.0233 (production) and 17.3118 (productivity) and $R^{2}$ values of the $0.2161,0.7936$ and 0.2778 respectively of the models estimating area, production and productivity imply that $21.61 \%, 79.36 \%$ and $27.78 \%$ of the variations in the trends in the performances of cotton were predicted by the independent variable (time). Similarly, the root mean square errors (RMSE) of the models estimating area (0.0468) production (0.0795) and productivity (0.0864) also justify that the model correctly predicts the trend since the RMSE of all the models were very close to zero. Hence from the values of F statistic, $R^{2}$ and RMSE in Table 2, it was justified that, the time variable in the models other than the intercept term were useful in predicting the trend.
Table 2: Trends in performance of cotton in Haryana (1967-2014)

\begin{tabular}{cccc}
\hline \multirow{2}{*}{ Variables } & \multicolumn{3}{c}{$\begin{array}{c}\text { Cotton } \\
\text { Production Productivity }\end{array}$} \\
\hline Overall Period & $0.0086^{* * *}$ & $0.0170^{* * *}$ & $0.0069^{* * *}$ \\
$(1967-2014)$ & & & \\
& $(0.0024)$ & $(0.0013)$ & $(0.0017)$ \\
Constant & $2.4029^{* * *}$ & $2.5372^{* * *}$ & $2.4127^{* * *}$ \\
& $(0.0774)$ & $(0.0374)$ & $(0.0481)$ \\
Observations & 47 & 47 & 47 \\
$R^{2}$ & 0.2161 & 0.7936 & 0.2778 \\
F-Statistic & 12.4065 & 173.0233 & 17.3118 \\
RMSE & 0.0468 & 0.0795 & 0.0864 \\
DW-Statistic & 1.9105 & 1.9127 & 2.0702 \\
$\rho$ & 0.7929 & 0.3394 & 0.4374 \\
\hline
\end{tabular}

Stars denote significance at ${ }^{* * *} p<0.01,{ }^{* *} p<0.05,{ }^{*} p<0.10$; Standard errors in parentheses are shown below the coefficients; Source: Author's calculation based on data obtained from published sources.

The study detected that, the trend (coefficient of time) in area, production and productivity was positive and highly significant at $p<0.01$. Thus, the area of harvest, production and productivity of cotton increased during the period 1967 to 2014. The area, production and productivity of cotton

Fig. 2: Trends in production of cotton in Haryana (1967-2014)

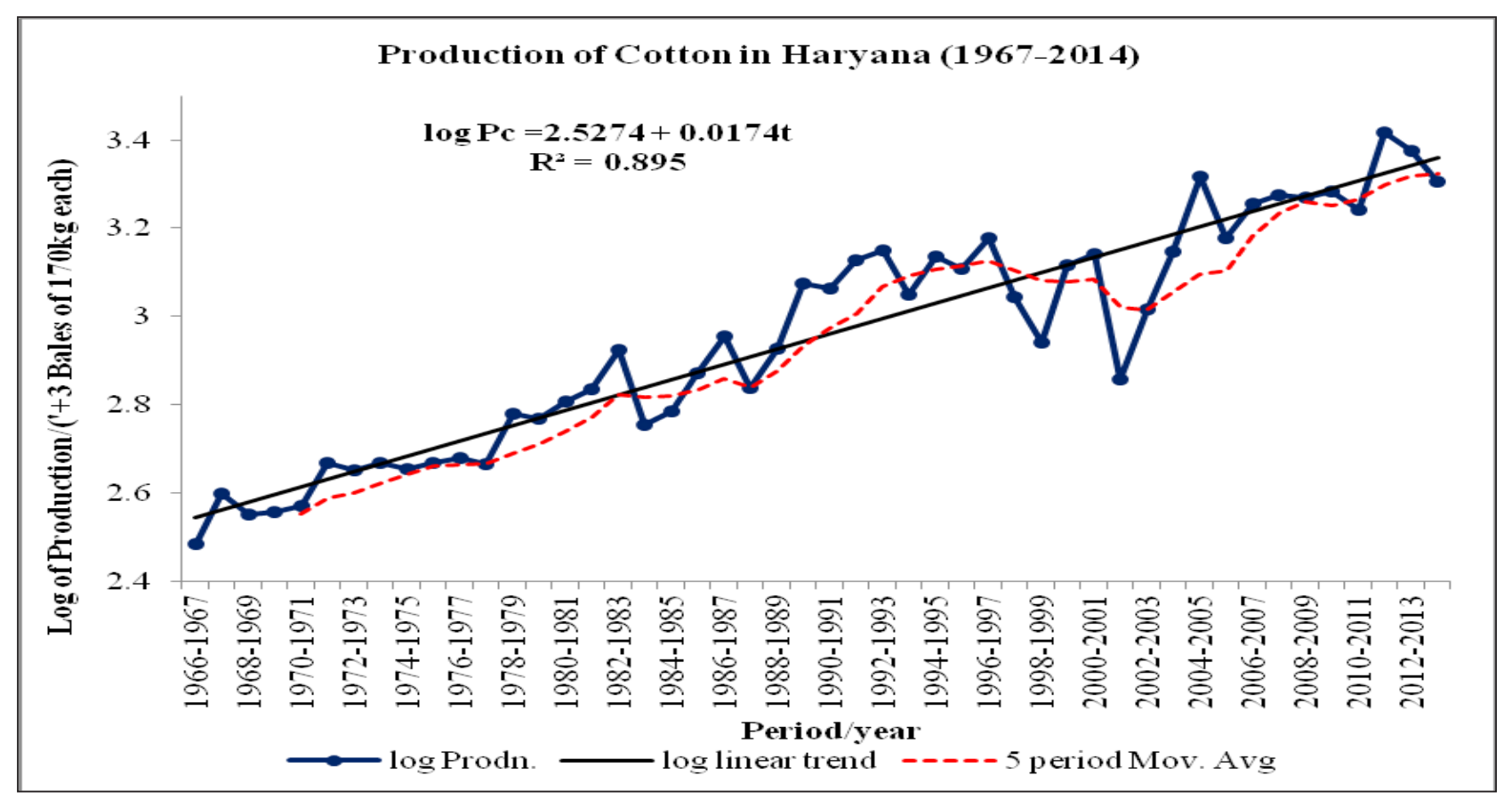

Source: Author's calculation based on data obtained from published sources 
increased by $0.0086,0.0170$ and 0.0069 respectively averagely every year which implied that the long run trends were increasing. The positive trend in the performances of cotton over the study period was due to good monsoon, higher producer prices, favourable government policies, fast adoption of Bt hybrids, adoption improved production technologies (Directorate of Cotton Development, 2009; Choudhary and Gaur 2010; Khadi 2012; Suresh et al. 2013).

\section{Compound growth rates of area, production and productivity Cotton (1967-2014)}

The compound growth rates of area, production and yield of cotton for the entire study period (1967 to 2014), analysed by the log linear model, were presented in Table 3. The study identified positive significant $(\mathrm{P}<0.01)$ growth in area, production and yield of cotton in Haryana. It was found that, during the period of 48 years, the area, production and yield of cotton increased at rate of 2.00, 3.99 and 1.66 percentage respectively. The identified scenario was similar and consistent with the findings of Agarwal et al. (2007) and Suresh et al. (2013). The introduction of hybrids in the late 1960s and Bt cotton in 2002 were meant to eliminate the yield constraints of cotton in India on the contrary, the study identified less growth in yield in Haryana. The findings were not surprising since the assertion of Chand and
Raju (2009) and Suresh et al (2013) suggested that the adoption of hybrids in Haryana were very low however the cultivation of open pollinated varieties of cotton were dominant.

Table 3: Compound growth rate of the performance of the cotton (1967-2014)

\begin{tabular}{cc}
\hline Performances of Wheat & $\begin{array}{c}\text { Compound Growth Rates } \\
(\mathbf{\%})\end{array}$ \\
\hline Area of Harvest & $2.00^{* * *}$ \\
Production & $3.99^{* * *}$ \\
Productivity & $1.60^{* * *}$ \\
\hline
\end{tabular}

Stars denote significance at ${ }^{* * *} p<0.01,{ }^{* *} p<0.05,{ }^{*} p<0.10$; Source: Author's calculation based on data obtained from published sources.

\section{Instability of area, production and productivity Cotton (1967-2014)}

The instabilities in area of harvest, production and productivity of cotton in the study area were presented in Table 4. The models goodness-of-fit tests and model implications were not different from that explained in Table 4 since the same values were used in the estimation of the instability (coefficient of variation around the trend) of the study period. The results indicated that the area of harvest, production and productivity of cotton exhibited inclined rate of instability at significance level of $1 \%$. The observed high instability rate in the

Fig. 3: Trends in productivity of cotton in Haryana (1967-2014)

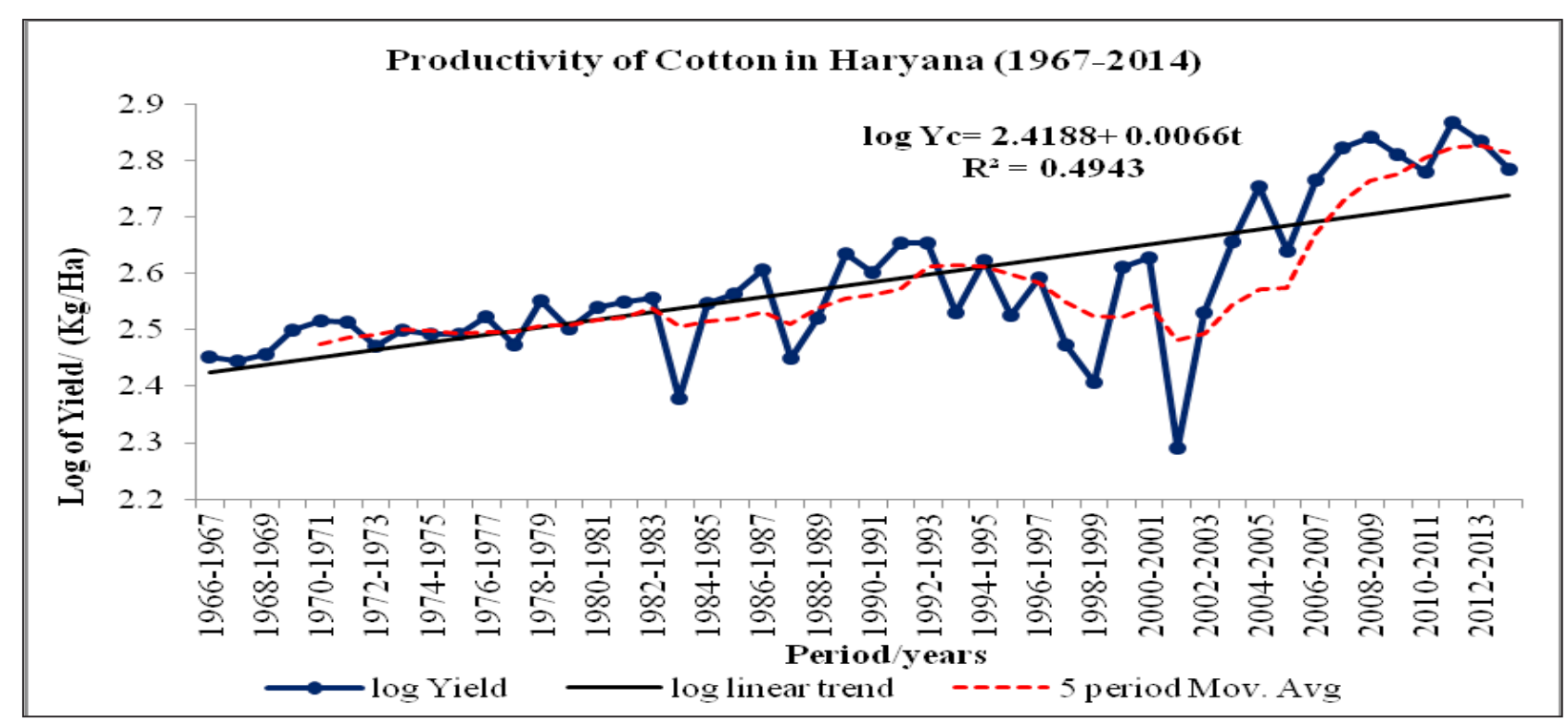

Source: Author's calculation based on data obtained from published sources 
Fig. 4: Trends in the performance of cotton in Haryana (1967-2014)

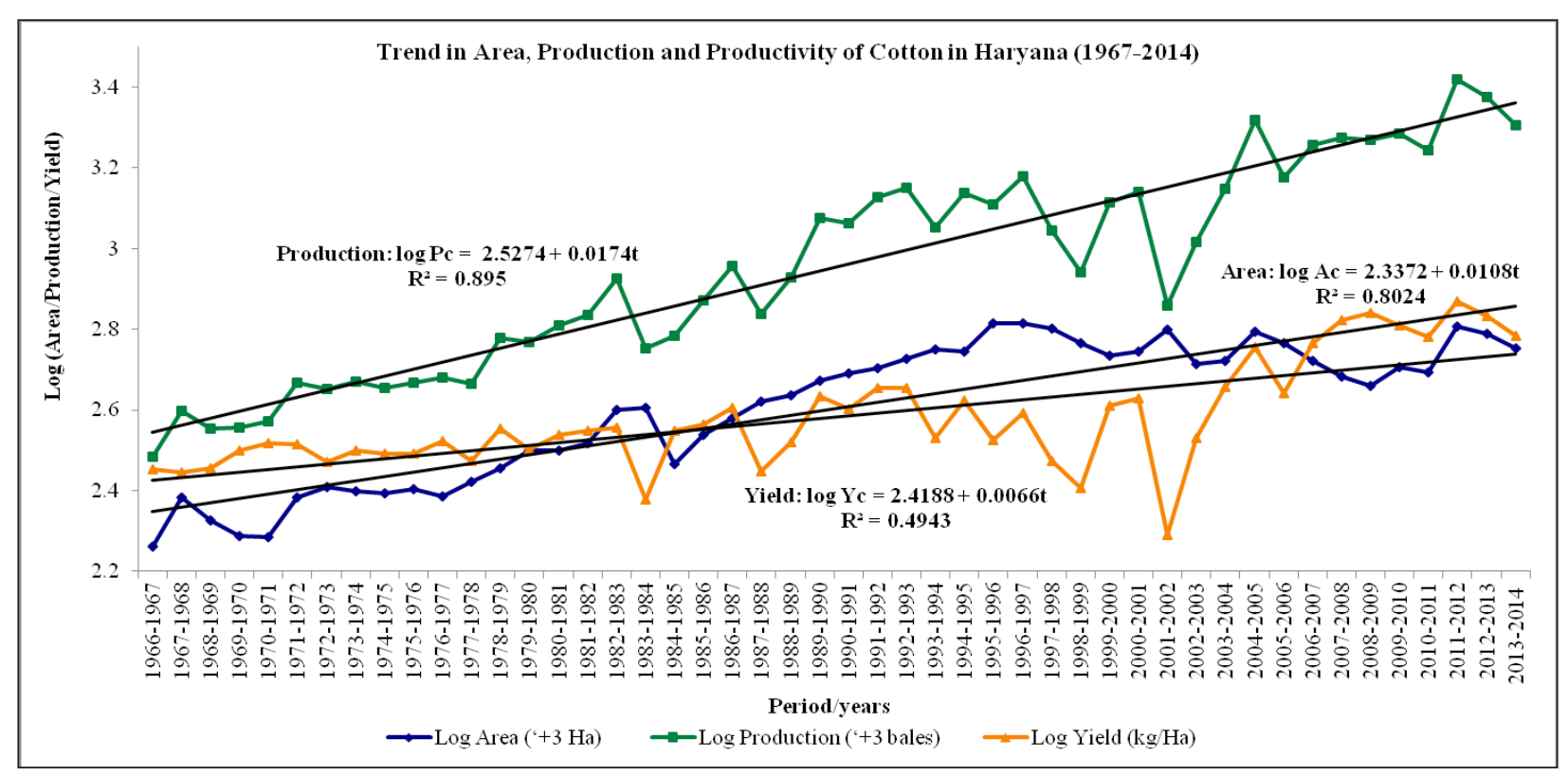

Source: Author's calculation based on data obtained from published sources

economic performance of cotton may be attributed to increased pest attack and subsequent high cost of plant protection.

Table 4: Instability of area, production and yield of the cotton (1967-2014)

\begin{tabular}{cccc}
\hline $\begin{array}{c}\text { Performances } \\
\text { of Cotton }\end{array}$ & $\mathbf{R}^{2}$ & $\mathbf{C V ~ ( \% )}$ & $\mathbf{C V}_{\mathbf{t}}(\mathbf{\%})$ \\
\hline Area of Harvest & 0.22 & 34.97 & $30.96^{* * *}$ \\
Production & 0.79 & 56.71 & $25.76^{* * *}$ \\
Productivity & 0.28 & 33.00 & $28.04^{* * *}$ \\
\hline
\end{tabular}

Stars denote significance at ${ }^{* * *} p<0.01,{ }^{* *} p<0.05,{ }^{*} p<0.10$; Source: Author's calculation based on data obtained from published sources

It is obvious from Table 4 that, instability in area was higher when compared to production and productivity of cotton which was contrary that in whole country reported by Narala and Reddy (2013). The instability for area was 30.96\% whereas that for production and productivity was $25.76 \%$ and $28.04 \%$ respectively. The highest instability of area among the performances of cotton might be due to the continuous expansion in area of cultivation during the 1967 to 2014. Though cotton is an irrigated crop in Haryana (Directorate of Cotton Development 2009; Suresh et al. 2013) hence, the expectation was that, the stability in its yield should be increased during the study period nonetheless the reverse was observed. The increased in instability of productivity of the crop may be associated to the reason that the crop might be cotton being moderately water intensive crop or less suitability the improved or hybrid varieties to the state due to erratic weather conditions.

\section{The effect of change in area on production of the major field crops in Haryana}

Goodness-of-fit measures indicated that the model (observations of 48) were highly significant at $\mathrm{P}<0.01$ judging by the $F$ statistic. Nonetheless the model showed a below average (weak) explanatory power considering the $R^{2}(14 \%)$.

Table 5: The effect of change in area on production of the major field crops in Haryana

\begin{tabular}{cc}
\hline Variables & Production \\
\hline Area of harvest & $2.0224^{* * *}$ \\
& $(0.7464)$ \\
Constant & 274.9553 \\
& $(395.5425)$ \\
Observations & 48 \\
$R^{2}$ & 0.14 \\
F-Statistic & $7.34^{* * *}$ \\
RMSE & 258.73 \\
\hline
\end{tabular}

Stars denote significance at ${ }^{* * *} p<0.01,{ }^{* *} p<0.05,{ }^{*} p<0.10$; Source: Author's calculation based on data obtained from published sources. 
The study noticed that there was a highly significant positive relationship between the area of harvest and production level. Thus expansion of area of cotton by a hectare resulted in increased in the level of production by almost 2 tonnes and vice versa. (see Table 5). As suggested by Chand and Raju (2009) and Directorate of Cotton Development (2009) as well as Suresh et al. (2013) that increased in production level in Haryana were not due to the adoption of hybrids and Bt cotton technology therefore it is more likely that expansion of area also contributed in production levels over the years.

\section{CONCLUSION}

The economic performance of cotton in Haryana over the study period witnessed a positive significant $(\mathrm{P}<0.01)$ trend. The annual growth rates of area of harvest, production and yield were $2.00 \%, 3.99 \%$ and $1.66 \%$ respectively. Instability was high and also inclined at an annual rate of $30.96 \%$ in area, $25.76 \%$ in production and $28.04 \%$ productivity. Expansion of area of harvesting resulted in improving production levels over the years. Despite progress in irrigation and other infrastructural developments in Haryana, performance of cotton especially productivity and production is characterised by less growth and high instability levels. The study therefore recommend that development and spread of innovations (such as development of high quality and improved open pollinated Bt varieties which is favourable to climatic conditions of Haryana) at an affordable price to farmers. Effective disease and pest control mechanism should be developed to check the perennial pests infestation in cotton and improving the growth and stability of the performance of the crop as well as curbing the over reliance on area for production enhancement in the state.

\section{REFERENCES}

Adam, B. and Dhruv, S. 2015. India: Cotton and Products Annual: Global Agricultural Information Network, GAIN Report Number: IN6046. Retrieved from United States Department of Agriculture Foreign Agriculture Service website https://www.fas.usda.gov/data/india-cotton-andproducts-annual-0.

Agarwal, I., Singh, S., Reddy A.R. and Venkatram, R. 2007. Total factor productivity of cotton in India. Retrieved from Technology Mission on Cotton Central Institute of Cotton Research website http://tmc.cicr.org.in/pdf/5.1-07-08.pdf.

Chand, R. and Raju, S.S. 2009. Instability in Indian Agriculture during different phases of Technology and Policy, Indian Journal of Agricultural Economics, 64(2): 187-207.

Choudhary, B. and Gaur, K. 2010. Bt Cotton in India: A Country Profile. ISAAA Series of Biotech Crop Profiles. ISAAA: Ithaca, NY.

Directorate of Cotton Development, Ministry of Agriculture. 2009. Report of Directorate of Cotton Development on Revolution in Indian Cotton. Retrieved from http://www. ncipm.org.in/NCIPMPDFs/Revolution_in_Indian_ Cotton.pdf

Khadi, B.M. 2012. Present status of Bt cotton in India, UAS, Dharwad, Karnataka, India. Retrieved from International Cotton Advisory Committee website https://www.icac. org/tis/regional_networks/asian_network/meeting_5/ documents/papers/PapKhadiB1.pdf

Narala, A. and Reddy, A.R. 2011. November. Analysis of Growth and Instability of Cotton Production in India. Paper presented at the World Cotton Research Conference on Technologies for Prosperity. Retrieved from website https://www.icac.org/wpcontent/uploads/2012/03/ wcrc5_proceedings_part8.pdf

Paltasingh, K.R. and Goyari, P. 2013. Analyzing Growth and Instability in Subsistence Agriculture of Odisha: Evidence from Major Crops. Agricul. Eco. Res. Rev., 26: 67-78.

Suresh, A., Palanisamy, R., Samuel, J. and Wankhade, S. 2013. Impact of technology and policy on growth and instability of agricultural production: The case of cotton in India. Indian Journal of Agricultural Sciences, 83(9): 939-948.

Tripathi, A. and Prasad, A.R. 2009. Agricultural development in India since independence: A study on progress, performance, and determinants. Journal of Emerging Knowledge on Emerging Markets, 1(1): 63-92. 